\title{
Rationale and Considerations for Proposed Near-Death Research in the Hospital Setting
}

\author{
Janice Miner Holden, Ed.D. \\ University of North Texas
}

ABSTRACT: Further research into the question of veridical perception during the "naturalistic" near-death out-of-body experience (nND OBE), that phase of the near-death experience in which the experiencer seems to be perceiving a normal earthly realm, would be of value to NDErs, their caregivers, and humanity in general. I propose a research procedure that targets visual perception during nND OBEs that occur in the hospital setting. I discuss unresolved issues in the design and implementation of such a procedure, and identify areas for further research.

A fascinating chapter in the history of parapsychological research began to unfold in the mid-1960s. Several years after the mysterious disappearance-and presumed death-of a frugal, reclusive miner of the Southwestern U.S., his will was found. In it, he left an estimated $\$ 174,000$ to "research or some scientific proof of a soul of the human body which leaves at death" (Fuller, 1969, pp. 20-21, 23). After a lengthy court battle, including an appeal, the money was awarded to the American Society for Psychical Research and was subsequently shared with the Psychical Research Foundation. Thus was funding provided for some of the most important research on out-of-body experiences (Rogo, 1986, pp. 13-14, 46ff).

Dr. Holden is currently Assistant Professor of Counselor Education at the University of North Texas. This paper was derived in part from her Ed.D. dissertation submitted to the Northern Illinois University Graduate School. Requests for reprints should be addressed to Dr. Holden at the Department of Counselor Education, College of Education, University of North Texas, P.O. Box 13857, Denton, TX 76203. 
James Kidd's bequest epitomizes the curiosity that most, if not all, humans feel regarding the possible existence of a human soul. This curiosity is peaked, in particular, by out-of-body experiences (OBEs), which "suggest a discreet aspect of self that may be able to exist apart from the physiological body" (Morris, 1978, pp. 11-12). The study of the near-death experience (NDE), which has been considered an extended out-of-body experience (Ring, 1980, p. 221; Sabom, 1982, p. 27), seems central to this question. However, even if evidence existed that the NDE, or portions of it, were "objectively real," the existence of the human soul would not be proved, because the NDErs who provided the evidence would not, in fact, have actually died; the evidence, whatever its nature, could be attributed to some function(s) of the living human body, whether or not those functions had as yet been identified and understood (Krishnan, 1982).

The question of the "objective reality" of the NDE is not, however, a pursuit without value. NDErs report relief at hearing normative information about NDEs (Moody, 1975, pp. 87-88; Oakes, 1981, p. 72; Sabom 1982, p. 139); presumably, information regarding the objective reality of the experience would contribute to such relief. And although NDErs are typically convinced of the objective reality of the NDE based on their own experience (Grey, 1985, p. 34; Jung, 1961, p. 295; Ring, 1980, pp. 82, 94; Ring, 1986; Sabom, 1982, p. 97), at least three cases have been cited in which experients wanted to verify that seemingly realistic NDE perceptions actually corresponded to "reality" (Clark, 1984, p. 243; Grey, 1985, pp. 37-38; Ring, 1984a, p. 43).

NDErs could also benefit if a better understanding of the "objective reality" of the NDE were available to those with whom the NDEr subsequently interacts. In a recent article containing guidelines about how best to intervene when one encounters a near-death experiencer, the authors stated that "caregivers should validate the individual's subjective experience in and of itself. However the individual or the caregiver interprets the NDE and its meaning, the experience itself must be recognized as subjectively real and powerful ..." (Greyson \& Harris, 1987, p. 46). In the absence of evidence regarding the objectivity of the experience, the caregiver is, indeed, limited to a phenomenological approach to intervention; this lack of evidence also limits the scope of the "straightforward factual information" (p. 46) the caregiver is encouraged to provide.

In addition, such evidence would probably limit the "biases" that caregivers are admonished to control (Clark, 1984, p. 247). Indeed, negative bias on the part of an interviewer has been detected by at least one NDEr (Sabom, 1982, p. 157), and such biases on the part of 
caregivers can have a profoundly negative impact on the NDEr's subsequent adjustment (Ring, 1984a, pp. 92-95). Thus further evidence regarding the "objective reality" of the NDE could enhance the degree to which caregivers can be helpful to NDErs.

Even for those of us who are neither NDErs nor their caregivers, a better understanding of the "objective reality" of the NDE could significantly enhance "our understanding of the death experience in human life" (Lundahl, 1982, p. 238). Such an understanding also bears upon our continued acceptance of the current scientific paradigm (Tart, 1974) as well as our beliefs about the fundamental nature of human beings (Garfield, 1979, p. 47; Ring, 1980, pp. 219-220; Sabom, 1982, p. 181; Tart, 1975; Widdison, 1982). Thus, although a better understanding of the "objective reality" of the NDE cannot prove the existence of the human soul, it nevertheless "touches upon the very essence and meaning of life" (Sabom, 1982, p. xii).

\section{A Review of Veridicality Research}

Years of research-and criticism of that research-have been spent on the phenomena of both the NDE and the closely related out-of-body experience. What has been said of NDEs could also be said of OBEs: "Their occurrence, as such, as well as their aftereffects, have now been documented amply and are no longer in doubt. The controversy ... has continued to be concerned with their interpretation and significance" (Ring, 1984b, p. 6). One expression of this controversy is a division among scholars: some believe that these phenomena involve either clairvoyance or actual perception during a "separation of 'something' ... from the physical body" (Ring, 1980, p. 221), whereas others believe that these phenomena are the result of very "down to earth" psychological or neurophysiological mechanisms (Irwin, 1985, pp. 219-220). This controversy between the "parapsychological" (Gabbard \& Twemlow, 1984, p. 134) and "imaginal" (Irwin, 1985, pp. 219-220) viewpoints continues to rage.

The fundamental issue in this controversy was encapsulated in Russell Noyes' (1979) observation that "those of us who only hear of [near-death experiences] have difficulty accepting these experiences as ... truth ..."(p. 86). As John Palmer (1978) so cogently pointed out, "It is essential to make a sharp distinction between the experience of being 'out-of-body' ... a and the possible fact of such separation. It is logically possible to have the experience of separation without actually separating, i.e., an 'illusory' experience" (p. 19). Despite the fact that "percep- 
tual realism is reported in the substantial majority of OBEs" (Irwin, 1985 , pp. 92-93) and that the NDE has nearly always been described as subjectively real (Grey, 1985, p. 34; Ring, 1980, pp. 82, 94), "The feeling of being 'out of the body' in itself means little without evidence that such a separation has in fact occurred" (Anderson, 1981, p. 10).

Although this question has been examined in a number of ways, the most common has been the study of veridical perception (Irwin, 1985, p. 59), that is, the extent to which $\mathrm{OB}$ perceptions "correspond precisely to the real (physical) world" (Irwin, 1985, p. 104). Such research has focused on the "naturalistic" OBE, in which the experient seems to be perceiving " a normal earthly ... realm" (Irwin, 1985, p. 7), usually the physical surroundings including and immediately adjacent to the experient's physical body (Irwin, 1985, p. 88; Ring, 1980, pp. 45-53). In the NDE, the naturalistic component seems to correspond to what Ring identified as "Stage Two" (1980, pp. 45ff) and what Sabom labeled the "autoscopic experience" (1982, p. 27). Indeed, the naturalistic ND OBE "provide[s] one of the few avenues through which to secure data about NDEs that can be independently corroborated" (Ring, 1984a, p. 41, referring to Sabom, 1982).

Cases in which experients claim to have acquired veridical information during the naturalistic experience have been replete in the literature of both the OBE (Alvarado, 1983, p. 12; Alvarado, 1984, p. 227; Blackmore, 1982a, p. 296; Blackmore, 1984, p. 234; Green, 1968, pp. 120-134) and NDE (Green \& Friedman, 1983, pp. 80-81; Grey, 1985, pp. 37-38; Oakes, 1981, p. 69; Moody, 1975, p. 100; Ring, 1980, pp. 50-52). Informal veridicality research initially involved ex post facto corroboration of experients' descriptions of physical events during their naturalistic ND OBEs. Convincing anecdotes were cited by Kimberly Clark (1984) and Michael Sabom (1981). Several such anecdotes were also noted by Raymond Moody $(1975$, p. 99) and Kenneth Ring (1984a, pp. 42, 50), but many could not be corroborated. In those cases in which hospital records were available for comparison, Moody (1975) found that the experients' accounts of events during their NDEs were "borne out" (p. 146). Whereas these observations were not the result of systematic investigation, they "[serve well] to indicate how in principle these accounts do lend themselves to external verification" (Ring, 1984 a, p. 43).

A more systematic study which, in an ex post facto design, compared NDErs' descriptions of their resuscitations (as purportedly viewed while out of body) with the medical records of their resuscitations, yielded strikingly positive results (Sabom, 1982). Nevertheless, 
Sabom's study has been criticized (Blackmore, 1985, pp. 79-80; Gabbard \& Twemlow, 1984, p. 224; Grosso, 1982, p. 213). And the ex post facto nature of the study makes it less scientifically credible than a double-blind study in which some perceivable stimulus could be manipulated, thus rendering the results amenable to statistical analysis.

Such research has been pursued in the laboratories of several OBE researchers, yielding both positive and negative results (Osis, 1974, 1975; Palmer \& Lieberman, 1985, 1976; Palmer \& Yassar, 1974; Tart, 1967, 1968). Upon assessing all the data, scholars of OB veridicality-both in and out of the context of the NDE-have drawn widely disparate conclusions (Gabbard \& Twemlow, 1984, pp. 128-136; Irwin, 1985, pp. 219-259). Some have judged claims of veridical perception to be "inconclusive and unconvincing" (Gabbard \& Twemlow, 1984, p. 230; see also Blackmore, 1982b, p. 5). Others have concluded that examination of the literature "will suffice . . . to convince all but the most diehard materialists of the reality of out-of-body experiences" (Ring, 1980, p. 222). Yet others have answered the question of OB veridical perception in the qualified affirmative (Rogo, 1984, pp. 35, 38) or very qualified affirmative (Osis, 1974, p. 111). It is fair to say that "today, the issue of whether the OBE is inherently psi-conducive remains a controversial question not only within parapsychology in general, but even among those researchers who have specialized in OBE research" (Rogo, 1984, pp. 29-30).

One potentially significant but as yet unconfirmed factor in the evaluation of past $\mathrm{OBE}$ veridicality research involves the issue of spontaneous versus induced OBEs. Most laboratory research has, of necessity, involved OBEs induced through some method such as progressive relaxation, meditation, hypnosis, audio-visual stimulation, and the like (Irwin, 1985, pp. 53ff). Celia Green (1968) first observed that inaccuracies in OB perception, "in common with other perceptual distortions, appear to be more commonly associated with ... voluntarily induced experiences than with single, spontaneously occurring experiences" (p. 74), that is, those that occur in the absence of any active or passive volition on the part of the experiencer. Green's observation has drawn both criticism (Blackmore, 1985, p. 81; Irwin, 1985, p. 107; Krishnan, 1983, p. 22) and support (Alvarado, 1982, p. 224; Irwin, 1985, pp. 72-73, 107; Smith \& Irwin, 1981, p. 4). Green (1968) also observed that the incidence of OB ESP was "particularly common in connection with ... experiences which occurred at the time of an accident or illness in hospital" (p. 20). Despite the possibility that the spontaneous OBE has been considered more promising in terms of 
more strongly evidencing veridical perception, "little has been done to study the phenomenon during spontaneous OBEs" (Alvarado, 1983, p. 11), of which the ND OBE is a form.

\section{Proposed Research Procedures}

If further ND OBE veridicality research is to be carried out, several questions must be addressed. What site would be most appropriate? What research design should be followed? What mode of perception should be targeted? How should the stimulus be presented, and what should be its specific content?

\section{Research Site}

The spontaneous nature of the NDE is a fundamental consideration in the selection of a research site.
[A] hindrance to NDE research arises from the difficulty of performing deliberate experiments. It is hard to conceive of circumstances that would justify the artificial induction of the physiological states associ- ated with near-death experiences. Investigations of the phenomenon must rely on naturally occurring "experiments" ... to confirm or disprove their hypotheses. (Bates \& Stanley, 1985, p. 543)

Although NDEs occur in practically every setting (Moody, 1975; Ring, 1980; Sabom, 1982), the one location in which they occur frequently enough to be warranted as a research site, and in which research controls are possible, is the hospital. Indeed, "much could be learned if psi investigation could be routinely incorporated into certain medical settings where one might suppose a gold mine of useful data awaits exploration" (Grosso, 1982, pp. 209-210).

The most frequently described location during the naturalistic ND OBE is in the vicinity of the physical body (Moody, 1985, p. 34; Ring, 1980 , p. 45; Sabom, 1982, p. 27). The naturalistic component of the NDE appears to occur randomly and cannot, therefore, be predicted (Greyson, 1984, p. 50; Ring, 1980, p. 131; Sabom, 1982, p. 194). Thus the most promising specific research site would be the hospital rooms in which near-death episodes most frequently occur, such as the Emergency Room and rooms of the intensive and cardiac care units. 


\section{Research Design}

In determining an appropriate research design for a veridicality study, previous research on OBEs provides direction. Historically, laboratory research on OBE veridicality has been conducted using subjects who claim to have OBEs (not associated with a near-death episode), whether spontaneous or induced, at relatively predictable times (Irwin, 1985, pp. 53-75). This research has taken three forms: attempts of the presumably exteriorized "something" to influence the environment, attempts to detect the "something" that leaves the body, and attempts by the OBEr to report targets at a remote location. Because it cannot be predicted whether a person encountering a neardeath episode will have an NDE, it would be nearly impossible-and possibly unethical - to coach someone before a potential future NDE to influence the environment in some particular way during the NDE. And since no reliable method has been established to detect the "something" that purportedly leaves the body (Irwin, 1985, pp. 61-66), pursuit of this research design is currently ill advised.

By far the most commonly employed index of phenomenal authenticity is that of veridical perception, or to use a less compromising term, veridical imagery. The experimental subject's ... experience is less viably regarded as artifactual fantasy if it incorporates substantially accurate imagery of some remote event, provided of course that this imagery cannot reasonably be attributed to such factors as prior knowledge, rational supposition, or direct sensory access. (Irwin, 1985 , p. 59)

In order to comply with this last criterion, the design should be "double blind"; that is, the exact content of the stimulus should be unknown to anyone until after the subject's perception of it has ostensibly occurred and the subject's recollection recorded. This enables correct answers to be attributed only to clairvoyance or actual $O B$ perception-whether theoretically attributed to actual exteriorization of "that which perceives" or to some as-yet-unknown physical perceptual process. The double blind procedure also eliminates the possibility that the subject acquired the information through intentional or unintentional communication with others. In addition, the design should eliminate the possibility of the "stacking effect" (Alvarado, 1982, p. 213), in which a single stimulus perceived by a series of subjects may be perceived by later subjects through telepathic communication with previous subjects, rather than from direct perception of the stimulus. 
These demands of a double-blind research design suggest some form of stimulus presentation in which combinations of elements are continuously randomly generated. The combinations would be recorded in code, including date and time. Thus decoding would occur only after a given naturalistic ND OBE subject had made a "guess" as to the specific nature of the stimulus. Some aspects of this type of design were pioneered by Charles Tart $(1967,1968)$ and refined by Karlis Osis (1973, 1975).

\section{Mode of Perception}

The next decision involves which, if any, mode of perception would be most promising in ND OBE veridicality research. Because subjects' descriptions of their ND OBEs tend to be predominantly visual (Irwin, 1985 , p. 97), vision seems to be the perceptual mode of choice. Another consideration involves how well the stimulus lends itself to double blind research design. Whereas touch stimuli are a possible candidate, the sense of touch seems absent during the ND OBE (Moody, 1975, p. 54 ; Ring, 1980 , p. 92). Stimuli to be heard or smelled would be difficult to isolate from others in the same room. Once again, visual stimuli appear to be most appropriate for this research design.

Therefore, the most promising research procedure would involve remote placement of visual stimuli in hospital rooms in which neardeath episodes most frequently occur. The stimuli would best involve continuously generated, random combinations of visual elements, recorded in code as to date, time, and particular element combination. Each patient who survived a near-death episode in one of the targeted rooms would be interviewed as to the nature of the visual stimulus, after which the stimulus record would be decoded and the subject's response evaluated for accuracy. Hypothetically, the responses of those subjects reporting a naturalistic ND OBE would significantly exceed chance accuracy and would be significantly more accurate than responses of other subjects.

\section{Unresolved Issues Regarding Research Design and Implementation}

Among the issues that remain to be resolved is the exact placement of the visual stimulus (or stimuli) in the hospital rooms. Obviously, the stimulus should be placed where it is most likely to be seen by the 
majority of naturalistic ND OBErs. However, conclusions about the typical naturalistic ND OB "locus of perception" have varied among researchers.

Moody (1975) described the typical subject of an ND OBE as "looking upon his own physical body from a point outside of it" (p. 34). This description did not specify any trend or pattern in the reported locus of perception relative to the physical body. Indeed, experients' quotes cited perceived loci of perception ranging from above to beside the physical body, at various heights and distances (pp. 34-50). However, an elevated perspective and, when indoors, a perceived locus of perception at the ceiling or in an elevated corner of the room was the most frequent location in studies by Ring (1980, p. 46) and Margot Grey (1985, p. 34). But neither researcher specified exactly how often this locus of perception occurred, nor did either researcher enumerate the variations on this theme. Sabom's (1982) focus on in-hospital naturalistic ND OBErs specified that 'the 'self' which had 'separated' from the unconscious physical body was perceived to be situated above the level of the physical body-a point specifically identified as 'ceiling height' in all but three cases [out of 32]" (pp. 27-28). He clarified that in all three exceptions, the individual was higher than ceiling height.

If the locus of perception is, indeed, usually at or near the ceiling, a visual stimulus could be placed in such a way as to be visible from only such a vantage point. However, considering the contradictory findings of various researchers regarding locus of perception, this question might best be undertaken in further research before implementation of a veridicality study. Similarly, further research seems warranted regarding two other unresolved issues: the specific content of the stimulus, and whether naturalistic ND OBErs are likely to be able to see and correctly report such a stimulus in numbers adequate to justify the research. Carlos Alvarado's (1982) point that "data on [perceptual organization during the $\mathrm{OBE}$ ] is scarce and has not been reported systematically" (p. 221) applies equally to the NDE. In particular, although spontaneous reports of some aspects of visual perception have been reported in the literature (Moody, 1875; Ring, 1980; Sabom, 1982), those making complete reference to visual processes during the naturalistic ND OBE are nonexistent.

Furthermore, based on research into other altered states of consciousness, systematic inquiry into perceptual phenomena and processes yields very different results than those gleaned from spontaneous reports alone (Kahn, Dement, Fisher, \& Barmack, 1962). When systematic research on $\mathrm{OB}$ visual perception has been undertaken, the samples sometimes included ND OBErs but did not usually analyze 
them separately (Blackmore, 1984; Green, 1968). Nevertheless, recent research has established that "certain features are ... significantly more often associated with NDEs than with other OBEs" (Gabbard \& Twemlow, 1984, p. 136), indicating that separate analysis might be appropriate. In addition, those attempts at systematic study of perceptual processes during the NDE (Greyson, 1984; Noyes \& Slymen, 1978-9), while providing direction, were not intended to study the phenomena in the depth necessary to resolve the issues discussed herein. Thus, a thorough study of visual perception during the naturalistic ND OBE seems warranted to resolve certain aspects of implementation of a hospital veridicality study.

An unresolved issue of another sort concerns the proposed stimulus that meets all the criteria for the "ideal" double-blind design. Development of a machine that would randomly select some combination of stimuli and would record that selection and the time of the selection in some codified form, would require some expertise in electronics. In addition, considering both that area of expertise and the need to produce enough of the machines to "cover" several rooms in each of a few hospitals, some considerable funding would be required.

A potential problem of yet another sort is the willingness of NDErs to be interviewed. Not only would this issue strongly influence the duration of the research study, it would also be an important factor in sampling bias. This issue has been touched on in the NDE literature (Ring, 1980), but has not been studied systematically.

A final concern involves location of a cooperating hospital or hospitals. "In order to substantiate . . claims of ND-related paranormal OB perception, it will be necessary in the future to obtain the cooperation of medical professionals. Obviously this will not be an easy task, given the stringent duties of physicians and nurses on the job" (Grosso, 1982, pp. 209-210)-not to speak of the possible skepticism, suspicion, or even contempt, with which a research proposal of the type described above might be met. Apparently, "efforts to conduct scientific research in the area of near-death are difficult, at best. Researchers not only fail to receive support from colleagues, but actually are pressured to abandon such research" (Widdison, 1982). This difficulty might be exacerbated if the researcher is seeking to conduct the study in a hospital in which he or she is not known professionally.

It is anticipated that these and other problems potentially associated with the suggested research described herein will be addressed by either this or another researcher. 


\section{Summary}

The question of veridical perception during the naturalistic ND OBE is deserving of further study. Such research promises to benefit NDErs, their caregivers, and those with whom they will interact subsequent to the NDE. In addition, the question of human perceptual ability that transcends the usual concept of physical limitation is central to beliefs held by humankind in general, about the nature of humans: are we limited to perception based on relatively known physical processes, or are we capable of as yet unknown physical or paranormal perceptual processes? "The possibility of verifying a large number of empirical claims stemming from the [naturalistic $\mathrm{OB}$ ] part of the near-death experience provides the strongest argument for [a paranormal] interpretation [of the NDE] ..." (Woodhouse, 1983, p. 71)-or for an interpretation involving unknown physical perceptual processes. Conversely, the failure to achieve such a verification could argue strongly against such interpretations. Avenues of empirical research into this question have not been exhausted. To this end, suggestions regarding a research design have been described and proposed herein, and problems in its refinement and implementation have been discussed. It is hoped that, as a result of this discussion, the proposed research will ultimately be pursued.

\section{References}

Alvarado, C. S. (1982). ESP during out-of-body experiences: A review of experimental studies. Journal of Parapsychology, 46, 209-230.

Alvarado, C. S. (1983). ESP and out-of-body experiences: A review of spontaneous studies. Parapsychology Review, 9 (4), 11-13.

Alvarado, C. S. (1984). Phenomenological aspects of out-of-body experiences: A report of three studies. Journal of the American Society for Psychical Research, 78, 219-240.

Anderson, R. I. (1981). Contemporary survival research: A critical review. Parapsychology Review, 12 (5), 8-13.

Bates, B. C., \& Stanley, A. (1985). The epidemiology and differential diagnosis of neardeath experience. American Journal of Orthopsychiatry, 55, 542-549.

Blackmore, S. J. (1982a). Have you ever had an OBE? The wording of the question. Journal of the Society for Psychical Research, 51, 292-302.

Blackmore, S. J. (1982b). Parapsychology - With or without the OBE? Parapsychology Review, 13(6), 1-7.

Blackmore, S. J. (1984). A postal survey of OBEs and other experiences. Journal of the Society for Psychical Research, 57, 225-244.

Blackmore, S. J. (1985). Susan Blackmore replies [Letter to the editor]. Anabiosis, 5(1), $79-82$. 
Clark, K. (1984). Clinical interventions with near-death experiencers. In B. Greyson \& C. P. Flynn (Eds.), The near-death experience: Problems, prospects, perspectives (pp. 242-255). Springfield, IL: Charles C. Thomas.

Fuller, J. G. (1969). The great soul trial. Toronto, Ontario: Macmillan.

Gabbard, G. O., \& Twemlow, S. W. (1984). With the eyes of the mind: An empirical analysis of out-of-body states. New York: Praeger.

Garfield, C. A. (1979). The dying patient's concern with 'life after death.' In R. Kastenbaum (Ed.), Between life and death (pp. 45-60). New York: Springer.

Green, C. E. (1968). Out-of-the-body experiences. Oxford: Institute for Psychophysical Research.

Green, J. T., \& Friedman, P. (1983). Near-death experiences in a Southern California population. Anabiosis, 3, 77-95.

Grey, M. (1985). Return from death: An exploration of the near-death experience. New York: Routledge \& Kegan Paul.

Greyson, B. (1984). The near-death experience scale. In B. Greyson \& C. P. Flynn (Eds.), The near-death experience: Problems, prospects, perspectives (pp. 45-60). Springfield, IL: Charles C. Thomas.

Greyson, B., \& Harris, B. (1987). Clinical approaches to the near-death experiencer. Journal of Near-Death Studies, 6, 41-52.

Grosso, M. (1982). Toward an explanation of near-death phenomena. In C. R. Lundahl (Ed.), A collection of near-death research readings (pp. 205-230). Chicago: Nelson-Hall.

Irwin, H. J. (1985). Flight of mind: A psychological study of the out-of-body experience. Metuchen, NJ: Scarecrow Press.

Jung. C. G. (1961). Memories, dreams, reflections. New York: Random House.

Kahn, E., Dement, W., Fisher, C., \& Barmack, J. E. (1962, September). Incidence of color in immediately recalled dreams. Science, 32, 1054-1055.

Krishnan, V. (1982). Out-of the-body vision. Parapsychology Review, 13(2), 21-22.

Lundahl, C. R. (1982). Directions in near-death research. In C. R. Lundahl (Ed.), A collection of near-death research readings (pp. 233-240). Chicago: Nelson-Hall.

Moody, R. A., Jr. (1975). Life after life. Covington, GA: Mockingbird.

Morris, R. L. (1978). Research on out-of-body experiences. In W. G. Roll \& R. L. Morris (Eds.), Research in Parapsychology 1977 (pp. 11-12). Metuchen, NJ: Scarecrow Press.

Noyes, R. (1979). Near-death experiences: Their interpretation and significance. In R. Kastenbaum (Ed.), Between life and death (pp. 73-88). New York: Springer.

Noyes, R., \& Slymen, D. J. (1978-79). The subjective response to life-threatening danger. Omega, 9, 313-321.

Oakes, A. R. (1981). Near-death events and critical care nursing. Topics in Clinical Nursing, 3(3), 61-78.

Osis, K. (1973). Toward a methodology for experiments on the out-of-the-body experiences. In W. G. Roll, R. L. Morris, \& J. D. Morris (Eds.), Research in Parapsychology 1972 (pp. 78-79). New York: Scarecrow Press.

Osis, K. (1974). Perspectives for out-of-body research. In W. G. Roll, R. L. Morris, \& J. D. Morris (Eds.), Research in Parapsychology 1973 (pp. 110-113). Metuchen, NJ: Scarecrow Press.

Osis, K. (1975). Perceptual experiments on out-of-body experiences. In J. D. Morris, W. G. Roll, \& R. L. Morris (Eds.), Research in Parapsychology 1974 (pp. 53-55). Metuchen, NJ: Scarecrow Press.

Palmer, J. (1978). The out-of-body experience: A psychological theory. Parapsychology Review, 9(5), 19-22.

Palmer, J., \& Lieberman, R. (1975). The influence of psychological set on ESP and out-ofbody experiences. Journal of the American Society for Psychical Research, 69, 193-213.

Palmer, J., \& Lieberman, R. (1976). ESP and out-of-body experiences: A further study. In J. D. Morris, W. G. Roll, \& R. L. Morris (Eds.), Research in Parapsychology 1975 (pp. 102-106). Metuchen, NJ: Scarecrow Press. 
Palmer, J., \& Vassar, C. (1974, March). ESP and out-of-the-body experiences: An exploratory study. Journal of the American Society for Psychical Research, 68, 256-280.

Ring, K. (1980). Life at death. New York: Coward, McCann \& Geoghegan.

Ring, K. (1984a). Heading toward omega. New York: William Morrow.

Ring, K. (1984b). Near-death studies: An overview. In B. Greyson \& C. P. Flynn (Eds.), The near-death experience: Problems, prospects, perspectives (pp. 5-16). Springfield, IL: Charles C. Thomas.

Ring, K. (1986, October). In search of the meaning of the near-death experience. Speech presented at a conference for The Center for Development in Ministry, Chicago, IL.

Rogo, D. S. (1984). Researching the out-of-body experience: The state of the art. Anabiosis, 4, 21-49.

Rogo, D. S. (1986). Life after death: The case for survival of bodily death. Wellingborough, Northamptonshire: Aquarian Press.

Sabom, M. B. (1982). Recollections of death: A medical investigation. New York: Harper and Row.

Smith, P., \& Irwin, H. (1981). Out-of-body experiences, needs and the experimental approach: A laboratory study. Parapsychology Review, 12(3), 1-4.

Tart, C. T. (1967). A second psychophysiological study of out-of-the-body experiences in a gifted subject. International Journal of Parapsychology, 9, 251-258.

Tart, C. T. (1968). A psychophysiological study of out-of-the-body experiences in a selected subject. Journal of The American Society for Psychical Research, 62, 3-27.

Tart, C. T. (1975). Some assumptions of orthodox, Western psychology. In C. T. Tart (Ed.), Transpersonal psychologies (pp. 59-111). New York: Harper \& Row.

Widdison, H. A. (1982). Near-death experiences and the unscientific scientist. In C. $R$. Lundahl (Ed.), A collection of near-death research readings (pp. 3-17). Chicago: NelsonHall.

Woodhouse, M. B. (1983). Five arguments regarding the objectivity of NDEs. Anabiosis, 3, 63-75. 